\title{
Heritability of Lifetime Income
}

\author{
Ari Hyytinen \\ Jyväskylä University School of Business and Economics and \\ Yrjö Jahnsson Foundation \\ Pekka Ilmakunnas \\ Aalto University School of Business and HECER \\ Edvard Johansson \\ Åland University of Applied Sciences \\ and \\ Otto Toivanen \\ Katholieke Universiteit Leuven
}

Discussion Paper No. 364

April 2013

ISSN 1795-0562

HECER - Helsinki Center of Economic Research, P.O. Box 17 (Arkadiankatu 7), FI-00014

University of Helsinki, FINLAND, Tel +358-9-191-28780, Fax +358-9-191-28781,

E-mail info-hecer@helsinki.fi, Internet www.hecer.fi 


\title{
HECER
}

Discussion Paper No. 364

\section{Heritability of Lifetime Income*}

\begin{abstract}
Using 15 years of data on Finnish twins, we find that $24 \%(54 \%)$ of the variance of women's (men's) lifetime income is due to genetic factors and that the contribution of the shared environment is negligible. We link these figures to policy by showing that controlling for education reduces the variance share of genetics by 5-8 percentage points; by demonstrating that income uncertainty has a genetic component half the size of its variance share in lifetime income; and by exploring how the genetic heritability of lifetime income is related to the macroeconomic environment, as measured by GDP growth and the Gini-coefficient of income inequality.
\end{abstract}

JEL Classification: J31, J62

Keywords: permanent income, income uncertainty, heritability, twins, genetics

Ari Hyytinen

Jyväskylä University School of Business

P.O. Box 35

FI-40014 University of Jyväskylä

Finland

e-mail: ari.hyytinen@jyu.fi

Edvard Johansson

Åland University of Applied Sciences

P.O. Box 1010

AX-22111 Mariehamn

Åland, Finland

e-mail: edvard.johansson@ha.ax
Pekka Ilmakunnas

Department of Economics

Aalto University School of Business

P.O. Box 21240

FI-00076 Aalto

Finland

e-mail: pekka.ilmakunnas@aalto.fi

Department of Managerial Economics, Strategy and Innovation

Katholieke Universiteit Leuven

Naamsestraat 69 bus 3500

B 3000 Leuven

Belgium

e-mail: otto.toivanen@econ.kuleuven.be

\footnotetext{
* We would like to thank Anders Björklund, Markus Jäntti, Jaakko Kaprio, Tuomas Pekkarinen and Roope Uusitalo for discussions, Jaakko Kaprio for access to the twin data and seminar participants at the Summer Meeting of the Finnish Economists (Jyväskylä, 2011), EALE (Bonn, 2012), VATT (Helsinki), and SOFI (Stockholm) for useful comments. This research has been financially supported by the Academy of Finland (project 127796). The usual caveat applies.
} 
A key concept in much of economics is the lifetime income of individuals. It is therefore not surprising that the determinants of income inequality and intergenerational income mobility are subject to an intensive research program. ${ }^{1}$ These determinants include shared environmental factors, such as a common family background, and genetically inherited traits. With a few recent exceptions (Björklund et al. 2005 and Benjamin et al. 2012) that all use Swedish data, the literature on the heritability of income has, however, relied on relatively poor proxies for lifetime income so far. ${ }^{2}$ Maybe even more relevantly, the literature on the heritability of economic outcomes has been criticized both in the past (Goldberger 1979) and more recently (Manski 2011) of being policy irrelevant. Our contribution to the debate is to provide empirical results that go beyond the standard variance decomposition and to suggest that the decomposition results can be linked to economic policy in a systematic way. To this end, our analysis makes use of Finnish data on a large number of identical (monozygotic, MZ) and non-identical (dizygotic, DZ) twin pairs born 1950-1957 and proceeds in four main steps.

In the first step, we use accurate administrative data on the twins' prime working-age incomes from 1990 to 2004 and standard behavioural genetics designs to measure the importance of genetic heritability and shared environmental factors in generating variation in the twins' lifetime income. These decompositions show that genes explain a high share of variation in lifetime income, whereas the shared environment explains very little. In this regard, our results are similar to those reported recently for Sweden by Benjamin et al. (2012). We find, moreover, that the genetic heritability is higher for men (50\%) than for women (30\%), but both sexes share the unimportance of the shared environment. These decomposition results are robust to a number of identification assumptions. ${ }^{3}$

\footnotetext{
${ }^{1}$ As Black and Devereux (2011) conclude in their recent review, an important and robust finding of this literature is that the relative equitable Nordic countries have high intergenerational mobility, exceeding clearly that of the UK and US. Consistent with this, the correlation of incomes among siblings is also much lower in the Nordic countries than in the U.S. (Solon 1999, Jäntti et al. 2002, Black and Devereux 2011).

${ }^{2}$ We return to this point in Section 2.

${ }^{3}$ An important caveat is that the results based on the standard variance decomposition are potentially driven by the restrictive assumptions that the method imposes. Björklund et al. (2005) find that once they relax some of them with the help of richer data, the share of income explained by genetic heritability is greatly reduced. When we use the point estimates of Björklund et al. (2005) to relax some of the same assumptions, we find our results to be largely robust in this respect.
} 
In the second step, we address the policy relevance of these findings by studying how sensitive the decomposition results are to the removal of the effect of education on lifetime income. ${ }^{4}$ We focus on schooling for three reasons: First, schooling is known to depend on genetic endowments (Behrman and Taubman 1989, Miller et al. 2001) and is hence a potential driver of the heritability of lifetime income. Second, schooling is in general thought to be a driving force behind (increases in) income inequality (e.g. Acemoglu and Autor 2011). ${ }^{5}$ Third, the recent evidence suggests that major schooling reforms have enhanced intergenerational earnings mobility. Meghir and Palme (2005) find, for example, that the Swedish educational reform increased the educational attainment and lifetime income of high ability students who had less educated parents. In similar vein, Pekkarinen, Uusitalo and Pekkala Kerr (2009), using income data from 1995-2000 for sons born 1960-1966, report that the intergenerational income elasticity for Finnish fathers and sons decreased from 0.30 to 0.23 because of a comprehensive schooling reform. Pekkarinen et al. hypothesize that the schooling reform benefited predominantly students from poorer families.

The individuals in our data effectively constituted the last cohort that obtained their primary and secondary schooling in the old, more selective, Finnish school system. Our results show that removing the effects of education on lifetime income of this cohort does not change the result that the shared environment plays a limited role, but reduces the share of the variance of lifetime income explained by genetic heritability by at least 10 percentage points. We argue that these results contribute to the policy debate about the effects of schooling reforms because they allow us to refine the interpretation of the school reform effect that Pekkarinen et al. uncover.

The third step of our empirical analysis addresses the critique that decomposition studies in economics do not fix the environment (a point emphasized by Manski 2011, see pp. 88). We take a step to this direction by studying how the decomposition results are affected by the macroeconomic environment. We find that the shared environment explains no variation in annual income and that both

\footnotetext{
${ }^{4}$ We remove the effect of schooling using two different methods in ways that are robust to the endogeneity of schooling (i.e., correlation between schooling and unobserved family and genetic endowments).

${ }^{5}$ This is important, because schooling has intergenerational persistence and is one of the most important determinants of long-term labor market outcomes.
} 
GDP growth and the Gini index of income inequality are positively associated with the variance share explained by genetic heritability. The latter result mirrors the point made by the critics that the decomposition results depend on the environment in which the data are generated. However, it also suggests that the variance decompositions may open a new way to understanding how the labor market allocation functions at different points of the business cycle. This may connect decomposition results with economic policy.

Finally, in the fourth step, we study an aspect of income that has not attracted attention before: heritability of income uncertainty (i.e., of the variation in annual income). We find that the genetic component of income uncertainty is roughly half of that of lifetime income and that the shared environment has a very limited role in explaining the variability of income uncertainty.

The remainder of this paper is organized as follows. In the next section, we first discuss the existing evidence. We then present the Finnish twin and register data in more detail. The third section describes how we measure lifetime income and estimate the contribution of shared environment and genetic heritability to its variance. There, we also discuss how we remove the effects of education, and report and discuss the results. The fourth section offers, to the best of our knowledge, the first ever look at macro-related variation in the heritability of income as well as the heritability of income uncertainty. Section 5 concludes.

\section{Existing evidence and Finnish twin data}

\subsection{Existing evidence}

The economic literature that uses twin data to analyse the determinants of the variance of income began with Taubman (1976). A great advantage of the twin data is that it allows measuring how genetic, shared environmental and individualspecific (non-shared environmental) factors contribute to it. The relative contributions of these factors to the variance can under certain assumptions be identified, because MZ and non-identical DZ twins have a shared (family) environment, but unlike the identical MZ twins, the non-identical DZ twins share, like non-twin 
siblings, only one-half of their genes on average. Greater similarity in outcomes between the MZ twins is therefore indicative of the importance of genes. ${ }^{6}$

Table 1 reports the sibling correlations of incomes for MZ and DZ twins as well as a standard additive variance decomposition implied by the siblings correlations (e.g. Posthuma et al. 2003). While the decomposition relies on a number of restrictive assumptions, the following preliminary observations can be made: First, the US estimates for the importance of the genetic component, $h^{2}$, are close to those reported for Sweden. Second, the genetic component accounts for as much as $40 \%$ of income variation. ${ }^{7}$ Third, the shared environment $\left(c^{2}\right)$ accounts for a relatively small fraction, say $10 \%$ or so, of the variance of the income. Fourth, the individual-specific (non-shared environmental) factors $\left(e^{2}\right)$ accounts roughly half of the variation in income. Fourth, with the exception of Miller, Mulvey and Martin (1997), the genetic component is lower for women than for men, though one should note that this evidence is exclusively from Sweden.

[Insert Table 1 here]

A particular challenge has been that the object of primary interest, lifetime income, has often been measured using poor proxies (Haider and Solon 2006, Böhlmark and Lindquist 2006). ${ }^{8}$ As Table 1 shows, most of the prior work uses a single cross-section and short-term income measures, such as annual earnings or hourly salary. ${ }^{9}$ Notable exceptions are Isacsson (1999) and Björklund et al. (2005), which both use three years of earnings data on Swedish twins over a spell of seven years, and Benjamin et al. (2012) who use up to 20 years of Swedish earnings data.

Besides the studies that focus on the heritability of income, there are a number of papers that are related to our work. A common denominator of them is that they all apply various variance decompositions to twin data in order to determine the importance of genetic and environmental factors for the variation of economic

\footnotetext{
${ }^{6}$ The importance of genetic heritability in explaining variation in outcomes does not imply that policy would be ineffective (Goldberger 1979, Manski 2011). Note also that regardless of the policy (ir)relevance of the genetic variance share, the variance share of the shared environment is often acknowledged to be of policy relevance (e.g., Taubman 1981).

${ }^{7}$ See Sacerdote (2011) for a review. We discuss the assumptions that underlie this calculation in the next section and relax some of them in our empirical analysis.

8 This may lead, for example, to a gross underestimation of the strength of the intergenerational links (Haider and Solon 2006).

${ }^{9}$ There are many studies that use MZ twins to estimate returns to education. However, they seldom report correlations of incomes for MZ and DZ pairs.
} 
outcomes (see also Sacerdote 2011 for a review). This branch of the literature include Behrman and Taubman (1989) and Miller et al. (2001), who investigate the genetic heritability of education, Miller et al. (1996) and Schnittker (2008), who focus on occupational status and socioeconomic position, and Nicolaou et al. (2008), who examine the effect of genetic heritability on the likelihood of becoming an entrepreneur. More recent work has extended the literature by studying the genetic heritability of the formation of preferences (Cesarini et. al 2009, and Simonson and Sela 2011) and financial decision-making (Barnea et al. 2010, and Cesarini et al. 2010). ${ }^{10}$

\subsection{Finnish Twin Data}

Our twin sample is based on the Older Finnish Twin Cohort Study (of The Department of Public Health in University of Helsinki) that we have matched to the Finnish Longitudinal Employer-Employee Data (FLEED) of Statistics Finland.

The Finnish Cohort Study was established in 1974 and was initially compiled from the Central Population Registry of Finland. Initial twin candidates were persons born before 1958 with the same birth date, commune of birth, sex, and surname at birth (Kaprio et al., 1979; Kaprio and Koskenvuo, 2002). A questionnaire was mailed to these candidates in 1975 to determine zygosity and to collect baseline data. ${ }^{11}$ Two follow-up surveys were then subsequently done in 1981 and 1990.

We focus on the youngest cohort, born in 1950-1957. This cohort obtained their primary and secondary schooling in the old, more selective, Finnish school system (for a nice description, see Pekkarinen et al. 2009). Our sample contains nearly all same-sex DZ and MZ twins of this cohort of the Finnish population. Most of the attrition is due to death (e.g., of fatal diseases or accidents) and migration.

\footnotetext{
${ }^{10}$ There are two other closely related branches in the literature. The first of them uses (non-twins) siblings and/or adoption data. Examples of this work include Björklund et al. (2006, 2007), Jäntti et al. (2001), Plug and Vijverberg (2003), and Sacerdote (2002, 2007). The second related branch focuses on the intergenerational mobility and elasticity of incomes; see Solon (1999) and Björklund and Jäntti (2009) for reviews.

${ }^{11}$ The zygosity of the twin pairs was determined using a deterministic method. It classified twin pairs on the basis of their responses to two questions on similarity in appearance in childhood. A subsample was taken for which the classification was redone using eleven blood markers. The classification results agreed almost completely, with the probability of misclassification of a blood marker concordant pair being 1.7\% (Kaprio et al., 1979).
} 
We had the twin data linked to FLEED using personal identifiers. FLEED is constructed from a number of different administrative registers on individuals, firms and establishments that are collected or maintained by Statistics Finland. Importantly for this study, FLEED includes information on salaries and other income, taken directly from tax and other registers. This implies that our income data do not suffer from underreporting or recall error. Nor is it top-coded. The income data in this study cover the years from 1990 to 2004.

\section{Heritability of lifetime income}

\subsection{Measuring lifetime income and its genetic variation}

\section{Lifetime income}

Because we use a sample of individuals born between 1950 and 1957, the individuals are from 33 to 40 years old at the beginning of our sample period in 1990 and from 48 to 55 years old at the end of the sample period in 2004. We thus observe the incomes of individuals who are at their prime working age. Our first measure for the lifetime income of an individual is the average of (the logarithm of) the individual's wage and salary earnings and self-employment income, calculated over the sample period. The findings of Haider and Solon (2006) for the U.S. and those of Böhlmark and Lindquist (2006) for Sweden suggest that this long-term sample average ought to be a reliable measure for the lifetime income.

Table 2 reports the means and standard deviations of unadjusted income and age, separately for MZ and DZ twins by gender.

\section{[Insert Table 2 here]}

Since we observe the individuals at different stages of their life-cycles, we adjust the incomes for age and year. We obtain the adjusted income from a regression of the log of annual income on a constant, fourteen year dummies and a third order polynomial of age, using the panel data on individuals but run separately for men 
and women. The age-adjusted lifetime income is then computed as the withinindividual average of these residuals. ${ }^{12}$

\section{Variance decompositions}

We measure the importance of genetic factors and shared environment for lifetime income using a regression approach. As a background to the models we first consider the "quick-and-dirty" approach (Posthuma et al., 2003) to the standard behavioral genetics decomposition. The genetic heritability of lifetime income is twice the difference in the correlations of the lifetime income between MZ and DZ twins, i.e., $h^{2}=2\left(r_{M Z}-r_{D Z}\right)$, and where the fraction of variance explained by the shared environment is $c^{2}=r_{M Z}-h^{2}=2 r_{D Z}-r_{M Z}$ and the fraction explained by non-shared environment is $1-h^{2}-c^{2}=1-r_{M Z}$. This model assumes i) that genes and environment have additive effects, ii) that MZ twins experience environments that are similar to those of DZ twins, iii) that there is no correlation between genetic factors and the shared environment (i.e., within-pair genetic differences are not correlated with the within-pair environmental differences), and iv) that there is no assortative mating, which would be the case if the long-term income genotypes of the parents were correlated. If there are dominant genetic influences ${ }^{13}$, the fraction of variance explained by them is $d^{2}=2 r_{M Z}-4 r_{D Z}$. This decomposition is a useful starting point as it provides us with guidance on the appropriate regression model.

Our primary approach is to use the regression model proposed by DeFries and Fulker (1985), and further developed by Waller (1994), Kohler and Rodgers

\footnotetext{
${ }^{12}$ When calculating the income measure we include only the years when the unadjusted income has been above 100 euros.

${ }^{13}$ Genetic effects on a trait are the sum of all effects of single genes and their interaction. Genes can have different effects due to genetic variation at a single base pair in the genome or to larger genetic structural variation. The variants at a locus in a gene are known as alleles. If the effect of carrying no, one or two alleles (as humans have two DNA strands) is additive on the trait, these are summed as additive genetic effects. Non-linear effects at a single locus are termed as dominance, while interactions between loci result in effects termed as epistasis. Additive effects are transmitted from parents to children, while effects due to dominance are not correlated between generations. Broad sense heritability refers to all kinds of genetic contributions, including additive, dominant, and epistatic. Narrow sense heritability refers solely to the additive genetic factors. (See Posthuma et al., 2003.)
} 
(2001) and Rodgers and Kohler (2005), among others. ${ }^{14}$ The simplest version of the DeFries and Fulker (DF) model is a regression model that relies on the assumptions of the additive genetic model, i.e. assumptions i)-iv). It is typically called the ACE-model and can be written as

$$
I N C_{1}=\beta_{0}+\beta_{1} I N C_{2}+\beta_{2} R+\beta_{3}\left(I N C_{2} R\right)+\varepsilon
$$

where $I N C_{1}$ is a measure of the lifetime income of twin 1 in a pair of twins, $I N C_{2}$ is the corresponding measure for twin 2 from the same pair of twins, $R$ is the coefficient of genetic relatedness ( $R=1.0$ for MZ twins and $R=0.5$ for DZ twins), $\varepsilon$ is an error term, and $\beta$ 's are regression coefficients. Given the assumptions of the ACE-model, $\beta_{1}$ and $\beta_{3}$ are unbiased estimates of $c^{2}$ and $h^{2}$, respectively (DeFries and Fulker, 1985, Rodgers and McGue, 1994). If the estimate of $\beta_{1}$ is negative, the model is not consistent with the decomposition and the shared environmental term should be dropped. It is often dropped also when the estimate is statistically not significant. The model is then called the AE-model.

Genetic effects need not be additive, but can be of a dominant form. Such effects can be accommodated in the DF-model by reformulating it to

$$
I N C_{1}=\beta_{0}+\beta_{2} R+\beta_{3}\left(I N C_{2} R\right)+\beta_{4}\left(I N C_{2} D\right)+\varepsilon
$$

where $D$ is the coefficient of dominant genetic relatedness (with $D=1$ for MZ twins and $\mathrm{D}=0.25$ for DZ twins; Waller, 1994, Rodgers et al. 2001). This model is often called the ADE-model. In (2), $\beta_{3}$ estimates narrow-sense heritability, $\beta_{4}$ the dominance effect, and $\beta_{3}+\beta_{4}$ estimates broad-sense heritability (Waller, 1994).

\footnotetext{
14 This model and its closely related variants are not unfamiliar to economists (see, e.g., Miller et al. 1996, 2001).
} 


\section{Main results}

Table 2 presents the correlation coefficients for our measure of lifetime income, separately for MZ and DZ twins by gender. In the ACE model it is required that the correlation of lifetime income within the MZ twin pairs, $r_{M Z}$, should be bigger than that of the DZ twin pairs, $r_{D Z}$, and $2 r_{D Z}$ should be at least as big as $r_{M Z}$. For men $r_{D Z}$ is so low that the latter condition does not hold. Therefore, the ACE model is not sensible. However, there may be dominance effects, as $2 r_{M Z}$ is higher than $4 r_{D Z}$ and the ADE model is therefore preferable. For women, the conditions for the ACE model hold. For them $4 r_{D Z}$ is higher than $2 r_{M Z}$, so the ADE model would not be sensible.

Table 3 presents the results of our DF-analyses for the ACE, AE, and ADE models. ${ }^{15}$ Recalling that $\beta_{1}$ and $\beta_{3}$ are estimates of the shared environment $\left(c^{2}\right)$ and genetic heritability $\left(h^{2}\right)$ in the ACE model we can see that the estimates are $24 \%$ and $10 \%$, respectively, for women. However, the estimate for $c^{2}$ is not significant. The AE model is more parsimonious as the shared environment term is dropped. It suggest that the estimate of $h^{2}$ is $37 \%$ for females. Based on the Akaike information criterion (AIC) the ACE model is, however, preferred. As expected, the ADE model does not give sensible results for females as the dominance effect is negative. ${ }^{16}$

For men the estimate of $c^{2}$ is negative in the ACE model. This suggests that alternative models ought to be considered and that dominance effects may be present (Waller, 1994, Rodgers et al., 2001). In the ADE-model, the narrow sense heritability, measured by the coefficient $\beta_{3}$ is $7 \%$ (but not significant) and the

\footnotetext{
${ }^{15}$ In (1) and (2), the value for twin 2 of a pair of twins is an explanatory variable for twin 1's outcome. However, it is not possible a priori to decide which of the twins is twin 1 and which is twin 2. The DF regression analysis is therefore performed in the double entry form, i.e. each twin pair is entered into the data twice: The first observation uses the outcome of twin 1 as the dependent variable and that of twin 2 as the explanatory variable. The second observation reverses the roles. This procedure means that standard errors are clustered at twin pair level for correct inference (see Kohler and Rodgers, 2001).

${ }^{16}$ The results of the DF regression for the ACE model are similar to what we would obtain from the simple decomposition based on the correlations. The correlations imply $h^{2}=2(0.339-0.220)=0.238 \approx 24 \%$ and $c^{2}=2 \times 0.220-0.339=0.101 \approx 10 \%$.
} 
dominance effect is $47 \%$. The broad heritability refers to the sum $\beta_{3}+\beta_{4}$ and is $54 \%$ for men. The sum is highly significant. The AE models suggest that the estimate of $h^{2}$ is $45 \%$ for males, but based on the AIC criterion the ADE model is preferred. $^{17}$

[Insert Table 3 here]

\section{Robustness}

We have checked the robustness of the results displayed in Table 3 in a number of ways:

First, we run the DF-regressions using a larger sample that includes both twin pairs born between 1945 and 1949 and those born between 1950 and 1957. There is some evidence for dominance effects for in these estimations. Based on the signs of the coefficients and the AIC criterion the AE model is preferred for females and the ADE model for males. The magnitude of genetic heritability implied by these models is 33\% for women and (broad sense heritability) 50\% for men (see Appendix 1, Table A1).

Second, we run the regressions using a broader income concept including capital income and transfers, such as unemployment benefits and parental leave benefits (see Appendix 1, Table A2). The magnitudes of the genetic effects are slightly higher than to those reported earlier in Table 4. For women the effect is over $40 \%$ in the AE model and for men close to $60 \%$ in the ADE model.

Third, we rerun the regressions using untrimmed, larger samples. Taking into account all nonzero (unadjusted) incomes gave results that were marginally lower than to those in Table 3: genetic heritability accounted for only $14 \%$ of the variation of lifetime income for women in the ACE model, but 32\% in the AE model. For men the share of genetic heritability was $48 \%$ in the ADE model. Finally, we included also the zero observations by using $\log ($ income +1 ) as the (unadjusted) annual income. In this case the genetic effect was $38 \%$ for women in the

\footnotetext{
17 The simple decomposition using the correlations again gives similar results. It implies $h^{2}=2(0.535-0.150)=0.770$ and $c^{2}=2 \times 0.150-0.535=-0.235$ in the ACE model. Since the estimate of $c^{2}$ is negative, adding it to $h^{2}$ gives $h^{2}=0.770-0.235=0.535\left(=r_{M Z}\right)$. In the ADE model the dominance effect is $d^{2}=2 \times 0.535-4 \times 0.150=0.470 \approx 47 \%$ and the additive effect is $0.535-0.470=0.065 \approx 7 \%$.
} 
AE model and 53\% for men in the ADE model. These results are available on request.

Fourth, the results are robust to not doing the age adjustment. These results are available on request, too.

\section{Comparison to Björklund et al. (2005)}

As a final robustness test, we address issues raised by Björklund et al. (2005). With the help of rich data on different types of Swedish siblings reared together and reared apart they were able to relax some of the assumptions of the standard decomposition models that we use. They relaxed one assumption at a time and found that i) the correlation of DZ twins' so-called genotypes was 0.43 instead of the assumed 0.5 ; ii) that the gene-environment correlation was not zero, but a small negative correlation existed (though it was statistically insignificant; and iii) the correlation of rearing environments for male (female) DZ twins reared together was $0.406(0.282)$ instead of the assumed 1.00. These findings, and especially the last one, lead them to conclude that the genetic component in income is much smaller than what is usually estimated.

The above results are potentially important for our findings. As we lack the kind of data Björklund et al. (2005) had, we resort to the following approach: First, we take those parameters they were able to estimate, and assume they apply to our data. This seems plausible given that our baseline results are so close to those reported in the studies that use the same decomposition model and Swedish data. Second, we base our calculations on the approach developed by Bowles and Gintis (2002). It relaxes the assumption that the environments experienced by MZ twins are similar to those of DZ twins, allows for a non-zero gene-environment correlation, and does not call for random mating. In particular, the model allows the environment of a sibling to depend on both the shared environmental factors and on genes. Appendix 2 describes our implementation of this approach in greater detail; it suffices to note here that the results support our main qualitative findings.

\subsection{The effect of education on income decomposition}

Education is without doubt the determinant of earnings that has attracted the most attention by economists. The way in which education is provided is also clearly a 
policy decision, as demonstrated e.g. by the studies of Meghir and Palme and Pekkarinen, Uusitalo and Pekkala Kerr cited above. The results of these authors suggest that changing the Swedish and Finnish educational systems from selective to comprehensive enhanced intergenerational mobility and benefited especially high ability students with poor parents. Another angle from which the effect of education on the decomposition of income is interesting is the observed increase in income inequality, especially during the last couple of decades. This phenomenon has been linked to a rising premium on (college) education (e.g., Acemoglu 1998).

To explore the importance of education for our main results, we run our DFregressions in two new ways. The idea here is that by netting out the effect of education on the variance of lifetime income, we can explore how important the interaction of schooling with the shared environment and the indirect genetic pathways are (i.e., how genetic and environmental factors affect lifetime income via their effect on schooling).

First, we add each individual's education (i.e., schooling in years) to the ACE, AE and ADE models as a new R.H.S. variable (see also Miller et al. 2001, or Nicolaou et al. 2008, who augment their variance decomposition models in various ways). The results of the augmented DF-models are displayed in panel A of Table 4. Second, as an alternative approach, we deduct the effect of education from the age-adjusted income of each individual directly before performing the decomposition estimation. We produce this estimated effect by first estimating a within-twin-differenced model using only MZ twins with the age-adjusted (log) lifetime income as the dependent variable and including only years of education as an explanatory variable. We then deduct the estimated return to actual schooling for each individual (both MZ and DZ) from the age-adjusted lifetime income. This approach accounts for the endogeneity of schooling with the shared environment and genetic traits. ${ }^{18}$ The results from these adjusted DF-regressions are displayed in panel B of Table 4.

\section{[Insert Table 4 here]}

\footnotetext{
${ }^{18}$ The estimated return to one more year of schooling was 0.058 (s.e. 0.020 ) for women and 0.080 (0.016) for men. The sample for women (men) consisted of 620 (494) twin pair observations.
} 
These results can be directly compared to those presented in Table 3. Starting from panel $\mathrm{A}$ of Table 4 where we add education as a control variable into the models, the first observation is that our results on the non-significance of the shared environment are unchanged: for the ACE model, the $c^{2}$ estimate is essentially zero for women, and negative for men. For women the preferred model by the AIC criterion is the ACE model. Comparing the $h^{2}$ estimates of the ACE models across Tables 3 and 4 suggests that controlling directly for education lowers the estimate of the genetic component by 5 percentage points for females. In the AE model the reduction is of the same order of magnitude. For men the ADE model has the lowest AIC value, but the estimate of the additive component of heritability is negative (although close to zero) in Table 4. Using therefore the AE model and comparing Tables 3 and 4, shows that the genetic component is reduced by 8 percentage points when education is controlled.

In panel B of Table 4 we deduct the direct effect of education. The results are very similar both with respect to the unimportance of the shared background and with respect to the change in the estimated variance share of genetic heritability: now the reduction is 3 percentage points for women in the ACE model (4 percentage points in the AE model), and 6 percentage points for men in the AE model.

\subsection{Summary and interpretation}

Taken together, we find that 24\% (54\%) of the variance of women’s (men's) lifetime income is due to genetic factors and that the contribution of the shared environment is small or negligible. Moreover, it seems that taking education into account reduces the variance share of genetic heritability by 5 percentage points for women and by 8 for men, but has no effect on the relative unimportance of the shared environment.

Given that the twins in our data constituted the last cohort that obtained their primary and secondary schooling in the old Finnish school system, these results have two policy implications:

On the one hand, the reduction in the degree of genetic heritability due to schooling suggests that the old, less comprehensive Finnish schooling system may have magnified the effects of genetic heritability on income. Another way to interpret the reduction in $h^{2}$ is that from 5 to 8 percentage points of the variance 
share of genetic heritability was channeled through schooling in the old Finnish selective school system. This could be due to e.g. parents reinforcing endowment differences among their children when deciding whom to educate further (see, e.g., Behrman et al. 1994).

On the other hand, both the shared (family) environment and genetic heritability are components of intergenerational income mobility. The previous analyses by Pekkarinen et al. (2009) and Meghir and Plame (2005) do not separate which of these two components drive the positive effect of the schooling reforms on the intergenerational income mobility. Our results suggest a limited role for the shared environment when the Finnish schooling reform was introduced. This means that the decrease in the intergenerational income elasticity documented by Pekkarinen et al. is related also to a reduction in the genetic heritability of incomes. $^{19}$

While tentative, the above observations allow us to refine the interpretation of Pekkarinen et al.’s findings. The observations suggest that the schooling reform may have enhanced intergenerational income mobility by increasing the likelihood that individuals with poorer endowments have been able to make and receive compensating human capital investments, irrespectively of their family resources and shared background.

This interpretation can also be linked to the results of Pekkala Kerr, Pekkarinen and Uusitalo (2013). They report that the Finnish school reform improved the military test scores on cognitive skills of individuals whose parents had only basic education, while affecting the population at large only marginally. ${ }^{20}$ They also argue that this improvement in tests scores can explain at most a small fraction of the decrease in the intergenerational income correlation reported by Pekkarinen et al. The results of Pekkala Kerr et al. suggest that the new comprehensive school offered more support to students with poorer endowments. This, coupled with our result that the shared environment played a limited role before the reform, suggests that such support allowed students with poorer endowments to make or receive compensating human capital investments. The Finnish comprehensive school reform may thus have led also to a leveling of incomes between

\footnotetext{
${ }^{19}$ This is so if one is willing to assume that the variance share of the shared environment did not increase when moving from the selective to the comprehensive schooling system.

${ }^{20}$ They report that the reform had only a small positive effect on the verbal test scores, but no effect in arithmetic or logical reasoning tests.
} 
students with different inherited traits, rather than only leveling differences in shared environments. ${ }^{21}$

This interpretation is supported by the prior results on the heritability of education: Silventoinen et al. (2004) have calculated that in the Older Twin Cohort Study - which is the data used in this study - the proportion of variation in education explained by additive genetic factors is 0.45 for men and 0.46 for women. The corresponding shares explained by shared environment are 0.36 and 0.39. ${ }^{22}$ A new data set, FinTwin16, includes birth cohorts 1975-1979, who have gone to school after the Finnish school reform. Using these data Latvala et al. (2011) show that the share of variation in education explained by additive genetic influences is 0.41 for men and 0.32 for women. The share of common environmental influences is 0.28 for males and 0.30 for females. ${ }^{23}$ These figures are consistent with the view that both genetic and shared environmental factors contribute less to the variance of schooling after the Finnish school reform.

\section{$4 \quad$ Variation of income over time}

\subsection{Macroeconomic conditions and heritability}

Given that most of the prior work uses a single cross-section and/or short-term income measures, a question of particular interest is whether the heritability estimates are stable in annual data. Figure 1 addresses this question and reports the results from behavioral genetic decompositions (DF-regressions) in which we use annual age-adjusted incomes, instead of our measures for lifetime income, as the dependent variable. Based on the signs of the coefficients and the AIC criterion, the AE model was preferred in 11 of the 15 years for women, the ADE model in 3 years and the ACE model in only one year. For men, the ADE model was pre-

\footnotetext{
${ }^{21}$ These interpretations are of course dependent on the Finnish institutional environment where e.g. university education has always been free.

${ }^{22}$ They obtained these results from a bivariate model of education and BMI. Very similar results are obtained from within twin pair correlations of education, reported in Silventoinen et al. (2004). The correlations suggest an ACE model with $h^{2}=0.48, c^{2}=0.35$ for men and $h^{2}=0.46, c^{2}=0.39$ for women .

${ }^{23}$ They obtained these results from a joint model for education and alcohol problems. Very similar results are obtained from within twin pair correlations of education, reported in Latvala et al. (2011). The correlations suggest an ACE model with $h^{2}=0.42, c^{2}=0.26$ for men and $h^{2}=0.28, c^{2}=0.30$ for women.
} 
ferred in 11 of the 15 years, and the AE model in 4 years. The ACE model could be ruled out in practically all of the years for both genders and we leave it out of the subsequent analysis. We present the figures by gender, separately for the $\mathrm{AE}$ and ADE-models (left axis) over time and plot also the real growth of GDP (right axis) and the Gini-index of income inequality (left axis). ${ }^{24}$ These two variables may co-vary with the share of heritability in the variance of annual incomes for a number of reasons: For example, the share of heritability may be lower during economic booms, if good macroeconomic conditions are associated with better employment and overall increases in income. One could also expect that the share of heritability is smaller in times of a more compressed income distribution.

\section{[Insert Figure 1 here]}

Figure 1 shows that the yearly heritability estimates are relatively stable (though not constant) for women. The yearly heritability estimates are, on average, slightly lower than the estimates we obtained using the lifetime income as the outcome measure. $^{25}$ This finding is in accordance with Benjamin et al. (2012), who find that heritability is somewhat lower in the annual data (see also Table 1). For men there is more variation over time in the results. Overall, it seems that the estimates may correlate with the GDP growth, especially for females. The variations in the Gini-index are so small that it is difficult to judge from the graph whether there is any correlation.

\section{[Insert Table 5 here]}

To study these links more systematically we regress the gender-specific yearly heritability estimates on a gender dummy, real growth of GDP and the Gini-index. The results are displayed in Table 5. The coefficient of GDP growth is positive and statistically significant (admittedly only at 7\% level) using the ADE models' heritability estimates. When we use the AE model heritability estimates, the coefficient of GDP growth is positive, but not statistically significant. The

\footnotetext{
24 The Gini index measures the inequality of gross income and is from the income distribution statistics of Statistics Finland. The GDP data is from the StatFin database.

${ }^{25}$ For men the averages of the heritability estimates in the AE and ADE models are 0.33 and 0.37, respectively. For women the average is 0.24 in all of the models.
} 
coefficient of the Gini-index is always positive, but marginally statistically significant (at 8\% level) only using the ADE model heritability estimates. When we used $\mathrm{AE}$ heritability estimates for women and $\mathrm{ADE}$ estimates for men, the results were very close to those obtained when the ADE model was used for both genders (results not shown). In terms of economic significance, we find that the effects, if taken at face value, are not negligible. ${ }^{26}$ This suggests that the economic environment may have a systematic influence on the measured heritability of income; this is something the literature has to our knowledge not explored systematically. ${ }^{27}$

\subsection{Heritability of income uncertainty}

How much of the variance in the within individual variation in annual incomes can be attributed to genetic, shared environmental and individual-specific factors? That is, how much of the variance in inter-temporal income uncertainty these factors account for? To the best of our knowledge, the prior literature does not provide an answer to these questions, despite the fact that income uncertainty and risks have been subject to a considerable research program.

As we understand it, estimates for the heritability of the second moment of the income distribution are not available in the prior literature for two reasons: First, earlier analyses have not relied on income data over several years, which is required to measure income uncertainty at the level of each individual. Second, measurement errors make the heritability analysis of income uncertainty difficult, as it is likely to bias the heritability estimates downwards. Having access to administrative tax register data on income alleviates to some extent these measurement issues.

To obtain a measure for income uncertainty at the level of individuals, we use the annual age and time adjusted income data for the same individuals and years we used in our main analysis and calculate the standard deviation of the

\footnotetext{
${ }^{26}$ Using the coefficient from the ADE model, our results suggest that the effect of GDP growth on the heritability of income between the years with highest and lowest GDP growth is (6.204 $(-6.013)) \times 0.005=0.06$. Using twice the standard deviation of GDP growth (3.37) gives a number half as large. For the Gini-index the figure using the largest and smallest values for the Gini-index and the coefficient from the ADE model is $(30.8-25.1) \times 0.010=0.06$. We acknowledge that these calculations are by no means conclusive, as they are based on a small sample and imprecisely estimated coefficients.

${ }^{27}$ Another way of interpreting this calculation is to see it as a demonstration of gene-environment correlation.
} 
income measure separately for each individual over the sample period (i.e., the standard deviation of the residual from the regression of logarithm of income on time effects and a polynomial of age). Table 6 displays the descriptive statistics for this measure in our sample. It shows that income uncertainty is, on average, greater for females than for males. The means of the uncertainty measure are very similar in the MZ and DZ subsamples.

\section{[Insert Table 6 here]}

Table 7 presents the results of the DF-analyses. For women the AE model is preferred, based on the signs of the coefficients and the AIC criterion. The estimate of $h^{2}$ is highly statistically significant and shows that $17 \%$ of the variance of women's income uncertainty can be attributed to genetic factors. The corresponding estimate of genetic heritability for men is 35\%, using the preferred ADE model. These findings confirm the conclusion that genes matter for the income risks that people face in their prime working age.

\section{[Insert Table 7 here]}

These results are robust to using the individual-specific average of the absolute value of the income measures (i.e. mean absolute value of the residual) as an alternative measure for the income uncertainty (results not shown).

\section{$5 \quad$ Conclusions}

Consistent with the results of Benjamin et al. (2012) for Sweden, we find that the heritability of long-term income is high in Finland with genetic heritability explaining over $20 \%$ of variation in lifetime income for women and over $50 \%$ for men. We also find that the shared (family) background plays a minor role in explaining variation in lifetime income. Genetically inherited traits may thus have a surprisingly large contribution to the correlation in the lifetime incomes of siblings and to intergenerational income persistence even in the equitable Nordic countries.

While the policy relevance of the variance share of genetic heritability has been questioned, our finding that controlling for differences in education reduces 
this share by $5-8 \%$ while not affecting the relative unimportance of the shared environment is, in our view, policy relevant: it means that the old, less comprehensive Finnish schooling system may have magnified the effects of genetic heritability on income. This could have been the case, for example, if parents reinforced at the time endowment differences among their children when deciding whom to educate further (see, e.g., Behrman et al. 1994). Moreover, it seems that the shared environment may have played a relatively limited role already at the time when the Finnish schooling reform, studied by Pekkarinen et al. (2009) and Pekkala Kerr et al. (2013), was introduced. If so, the decrease in the intergenerational income elasticity documented by Pekkarinen et al. may be at least as much related to lower genetic heritability of incomes as to a reduced importance of nongenetic (family) resources. This viewpoint suggests that the schooling reform may have enhanced intergenerational income mobility e.g. by increasing the likelihood that individuals with poorer individual endowments have been able to make or receive compensating human capital investments. This means that the Finnish comprehensive school reform led to a leveling of incomes between students with different inherited traits in addition to possibly leveling differences in shared environments. Consistent with this view, a part of the good average performance of the Finnish students in international comparisons, such as the Programme for International Student Assessment (PISA), is apparently attributable to the low share of badly performing students (i.e., the low variation in student scores; see OECD 2010).

We also provide novel evidence on the heritability of income uncertainty (i.e., in annual variation of income) and some evidence of gene-environment interaction that is related to the business cycle and income distribution. These findings suggest that variations in labor market conditions that are related to the state of the macroeconomy have a direct impact on the variance share of income explained by genetic heritability, thereby linking the variance share to economic policy. 


\section{References}

Acemoglu, D. 1998. Why Do New Technologies Complement Skills? Directed Technical Change and Wage Inequality. Quarterly Journal of Economics, 113(4): 1055-1089.

Acemoglu, D. and Autor, D. 2011. Skills, Tasks and Technologies: Implications for Employment and Earnings. In Ashenfelter O. and Card D. (eds.) Handbook of Labor Economics 4B, Elsevier.

Ashenfelter, O. and Krueger, A. 1994. Estimates of the Economic Return to Schooling from a New Sample of Twins. American Economic Review 84(5): 1157-1173.

Ashenfelter, O. and Rouse, C. 1998. Income, Schooling and Ability: Evidence from a New Sample of Identical Twins. Quarterly Journal of Economics 113(1): 253-284.

Barnea, A., Cronqvist, H., Siegel, S. 2010. Nature or Nurture: What Determines Investor Behavior? Journal of Financial Economics 98(3): 583-604.

Becker, G.S. and Tomes, N., 1979. An Equilibrium Theory of the Distribution of Income and Intergenerational Mobility. Journal of Political Economy 87(6): 11531189 .

Behrman, S. and Taubman, P. 1989. Is Schooling “Mostly in the Genes?” NatureNurture Decomposition Using Data on Relatives. Journal of Political Economy 97(6): 1427-1446.

Benjamin, D.J., Cesarini, D., Chabris,C.F., Glaeser, E.L., Laibson, D.I., Gudnason, V., Harris, T.B., Launer, L.J., Purcell, S., Smith, A.V., Johannesson, M., Magnusson, P.K.E., Beauchamp, J.P., Christakis, N.A., Atwood, C.S., Hebert, B., Freese, J., Hauser, R.M., Hauser, T.S., Grankvist, A., Hultman, C.M., and Lichtenstein, P. 2012. The Promises and Pitfalls of Genoeconomics. Annual Review of Economics 4: 627-662

Björklund, A. and Jäntti, M. 2009. Intergenerational Income Mobility and the Role of Family Background. In W. Salverda, B. Nolan, and T.M. Smeeding, eds., The Oxford Handbook of Economic Inequality. Oxford: Oxford University Press, 491-521

Björklund, A., Lindahl, M. and Plug, E. 2006. The Origins of Intergenerational Associations: Lessons from Swedish Adoption Data. Quarterly Journal of Economics 121(3): 999-1028.

Björklund, A., Jäntti, M. and Solon, G. 2005. Influences of Nature and Nurture on Earnings Variation: A Report on a Study of Various Sibling Types in Sweden. In S. Bowles, H. Gintis, and M. Osborne, eds., Unequal Chances: Family Background and Economic Success. New York: Russell Sage Foundation, 145-164.

Björklund, A., Jäntti, M. and Solon, G. 2007. Nature and Nurture in the Intergenerational Transmission of Socioeconomic Status: Evidence from Swedish Chil- 
dren and Their Biological and Rearing Parents. The B.E. Journal of Economic Analysis \& Policy: Advances 7(2): Article 4.

Black, S. E. and Devereux, P.J. 2011. Recent Developments in Intergenerational Mobility. In O. Ashenfelter and D. Card, eds., Handbook of Labour Economics, Amsterdam: Elsevier, Vol. 4B, 1487-1541.

Bowles, S. and Gintis, H. 2002. The Inheritance of Inequality. Journal of Economic Perspectives 16(3): 3-30.

Böhlmark, A. and Lindquist, M. 2006. Life-Cycle Variations in the Association between Current and Lifetime Income: Replication and Extension for Sweden. Journal of Labor Economics 24(4): 879-896.

Cesarini, D., 2010. The Effect of Family Environment on Productive Skills, Human Capital and Lifecycle Income, In D. Cesarini: Essays on Genetic Variation and Economic Behavior, PhD thesis, MIT.

Cesarini, D., Dawes, C., Johannesson, M., Lichtenstein, P. and Wallace, B. 2009. Genetic Variation in Preferences for Giving and Risk Taking. Quarterly Journal of Economics 124(2): 809-842.

Cesarini, D., Johannesson, M., Lichtenstein, P., Sandewall, Ö. and Wallace, B. 2010. Genetic Variation in Financial Decision Making. Journal of Finance 65(5): 1725-1754.

DeFries, J. and Fulker, D. 1985. Multiple Regression Analysis of Twin Data. Behavior Genetics 15(5): 467-473.

Falconer, D. 1981. Introduction to Quantitative Genetics. New York. Longman.

Goldberger, A. 1979. Heritability. Economica 46(184): 327-347.

Haider, S. and Solon, G. 2006. Life-Cycle Variation in the Association between Current and Lifetime Earnings. American Economic Review 96(4): 1308-1320.

Harding, D.J., Jencks, C., Lopoo, L.M., and Mayer, S.E. 2005. The Changing Effect of Family Background on the Incomes of American Adults. In S. Bowles, H. Gintis, and M. Osborne, eds., Unequal Chances: Family Background and Economic Success. New York: Russell Sage Foundation, 100-144.

Holmlund, H. 2007. Intergenerational Mobility and Assortative Mating: Effects of an Educational Reform. Unpublished working paper, London School of Econnomics.

Isacsson, G. 1999. Estimates of the Return to Schooling in Sweden from a Large Sample of Twins. Labour Economics 6: 471-489.

Johnson, W. and Krueger, R.F. 2005. Genetic Effects on Physical Health: Lower at Higher Income Levels. Behavior Genetics 35: 579-590. 
Jäntti, M., Österbacka, E., Raaum, O., Eriksson, T. and Björklund, A. 2002. Brother correlations in earnings in Denmark, Finland, Norway and Sweden compared to the United States, Journal of Population Economics 15(4): 757-772.

Kaprio, J. and Koskenvuo, M. 2002. Genetic and Environmental Factors in Complex Diseases: The Older Finnish Twin Cohort. Twin Research 5(5): 358-365.

Kaprio, J. Koskenvuo, M. Artimo, M. Sarna, S. Rantasalo, I. 1979. The Finnish Twin Registry: Baseline Characteristics. Section I. Materials, Methods, Representativeness and Results for Variables Special to Twin Studies. Department of Public Health, University of Helsinki, Series M 47.

Kohler, H. and Rodgers, G. 2001. DF-Analyses of Heritability with Double-Entry Twin Data: Asymptotic Standard Errors and Efficient Estimation. Behavior Genetics 31(2): 179-192.

Latvala, A., Dick, D.M., Tuulio-Henriksson, A., Suvisaari, J., Viken, R.J., Rose, R.J. ja Kaprio, J. 2011. Genetic correlation and gene-environment interaction between alcohol problems and educational level in young adulthood. Journal of Studies on Alcohol and Drugs 72(2): 210-220.

Manski, C. 2011. Genes, Eyeglasses, and Social Policy, Journal of Economic Perspectives, 25(4): 83-94.

Meghir, C., and Palme M. 2005. Educational Reform, Ability, and Parental Background. American Economic Review 95(1): 414-424.

Miller, P., Mulvey, C., and Martin, N. 1995. What Do Twins Studies Reveal About the Economic Returns to Education? A Comparison of Australian and U.S. Findings. American Economic Review 85(3): 586-599.

Miller, P., Mulvey, C., and Martin, N. 1996. Multiple Regression Analysis of the Occupational Status of Twins: A Comparison of Economic and Behavioral Genetic Models. Oxford Bulletin of Economics and Statistics 58(2): 227-239.

Miller, P., Mulvey, C., and Martin, N. 1997. Family Characteristics and the Returns to Schooling: Evidence on Gender Differences from a Sample of Australian Twins. Economica 64: 137-154.

Miller, P., Mulvey, C., and Martin, N. 2001. Genetic and Environmental Contributions to Educational Attainment in Australia. Economics of Education Review 20(3): 211-224.

Miller, P., Mulvey, C., and Martin, N. 2006. The Returns to Schooling: Estimates from a Sample of Young Australian Twins. Labour Economics 13: 571-587.

Nicolaou, N., Shane, S., Cherkas, L., Hunkin, J. and Spector, T. 2008. Is the Tendency to Engage in Entrepreneurship Genetic? Management Science 54(1): 167179.

OECD (2010), PISA 2009 Results: What Students Know and Can Do - Student Performance in Reading, Mathematics and Science (Volume I). 
Pekkala Kerr, S. Pekkarinen, T., Uusitalo, R., 2013. School Tracking and Development of Cognitive Skills, Journal of Labor Economics 31(3).

Pekkarinen, T., Uusitalo, R., and Pekkala Kerr, S., 2009. School Tracking and Intergenerational Income Mobility: Evidence from the Finnish Comprehensive School Reform, Journal of Public Economics 93: 965-973.

Plug, E. and Vijverberg, V. 2003. Schooling, Family Background, and Adoption: is it Nature or is it Nurture? Journal of Political Economy 111(3): 611-641.

Posthuma, D., Beem A. L., de Geus, E. J. C., van Baal, G. C. M., von Hjelmborg Jacob B., I. I., and Boomsma, D. I. 2003. Theory and Practice in Quantitative Genetics, Twin Research 6(5): 361-376.

Rodgers, J. and MacGue, H. 1994. A Simple Algebraic Demonstration of the Validity of the DeFries-Fulker Analysis in Unselected Samples with Multiple Kinship Levels. Behavior Genetics 24(2): 259-262.

Rodgers, J., Kohler, H., Kyvik, K. and Christiansen, K. 2001. Modelling of Human Fertility: Findings from a Contemporary Danish Twin Study. Demography 38(1): 29-42.

Rodgers, J. and Kohler, H. 2005. Reformulating and Simplifying the DF Analysis Model. Behavior Genetics 35(2): 211-217.

Sacerdote, B. 2002. The Nature and Nurture of Economic Outcomes. American Economic Review (Papers and Proceeedings) 92(2): 344-348.

Sacerdote, B. 2007. How Large Are The Effects from Changes in Family Environment? A Study of Korean American Adoptees. Quarterly Journal of Economics 122(1): 119-157.

Sacerdote, B. 2011. Nature And Nurture Effects On Children's Outcomes: What Have We Learned From Studies Of Twins And Adoptees?. In J. Benhabib, A. Bisin, and M.O. Jackson, eds., Handbook of Social Economics, Amsterdam: Elsevier, 1-30.

Schnittker, J. 2008. Happiness and Success: Genes, Families, and the Psychological Effects of Socioeconomic Position and Social Support. American Journal of Sociology 114: 233-259.

Shane, S. 2010.Born Entrepreneurs, Born Leaders. How Your Genes Affect Your Work Life. New York: Oxford University Press.

Silventoinen, K., Sarlio-Lähteenkorva, S., Koskenvuo, M., Lahelma, E., and Kaprio, J. 2004. Effects of Environmental and Genetic Factors on EducationAssociated Disparities in Weight and Weight Gain: A Study of Finnish Adult Twins. American Journal of Clinical Nutrition 80(4): 815-822. 
Simonson, I. and Sela, A. 2011. On the Heritability of Consumer Decision Making: An Exploratory Approach for Studying Genetic Effects on Judgment and Choice . Journal of Consumer Research 37(2).

Solon, G. 1999. Intergenerational Mobility in the Labor Market. In O.C. Ashenfelter and D. Card, eds., Handbook of Labor Economics, Vol. 3A. Amsterdam: Elsevier, 1761-1800.

Taubman, P. 1976. The Determinants of Earnings: Genetics, Family, and Other Environments: A Study of White Male Twins. American Economic Review 66(5): 858-870.

Taubman, P. 1981. On Heritability. Economica 48: 417-420.

Waller, N. 1994. A DeFries and Fulker Regression Model for Genetic Nonadditivity. Behaviour Genetics 24(2): 149-153. 
Table 1: Earlier studies on the genetic heritability of income

\begin{tabular}{|c|c|c|c|c|c|c|c|c|}
\hline Source & Income measure & Gender & Country & $\mathrm{r}_{\mathrm{Mz}}$ & $r_{D Z}$ & $h^{2}$ & $\mathrm{c}^{2}$ & $\mathrm{e}^{2}$ \\
\hline Taubman (1976, Table 2) & Log of annual income & Men & USA & 0.54 & 0.30 & 0.48 & 0.06 & 0.46 \\
\hline Ashenfelter, Krueger (1994, Table 2) & Log of hourly wage & Both & USA & 0.56 & 0.36 & 0.40 & 0.17 & 0.44 \\
\hline Ashenfelter, Rouse (1998) & Log of hourly wage & Both & USA & 0.63 & 0.37 & 0.52 & 0.11 & 0.37 \\
\hline Johnson, Krueger (2005, Table IV) & Log of annual household income & Both & USA & 0.38 & 0.13 & 0.38 & 0.00 & 0.62 \\
\hline Schnittker (2008, Table 1) & Log of annual income & Both & USA & 0.40 & 0.26 & 0.28 & 0.12 & 0.60 \\
\hline Miller, Mulvey, Martin (1995, Table 2) & Log of average occupational income & Both & Australia & 0.68 & 0.32 & 0.68 & 0.00 & 0.32 \\
\hline Miller, Mulvey, Martin (1997, Table 2) & Log of average occupational income & Men & Australia & 0.59 & 0.56 & 0.07 & 0.52 & 0.41 \\
\hline Miller, Mulvey, Martin (1997, Table 2) & Log of average occupational income & Women & Australia & 0.56 & 0.28 & 0.55 & 0.01 & 0.44 \\
\hline Miller, Mulvey, Martin (2006, Table 2) & Log of annual income & Both & Australia & 0.50 & 0.14 & 0.50 & 0.00 & 0.50 \\
\hline Isacsson (1999, Table 2) & Average of 3 year log incomes & Both & Sweden & 0.68 & 0.46 & 0.44 & 0.24 & 0.32 \\
\hline Björklund, Jäntti, Solon (2005, Table 1) & Average of 3 year log incomes & Men & Sweden & 0.36 & 0.17 & 0.36 & 0.00 & 0.64 \\
\hline Björklund, Jäntti, Solon (2005, Table 1) & Average of 3 year log incomes & Women & Sweden & 0.31 & 0.12 & 0.31 & 0.00 & 0.69 \\
\hline Cesarini (2010, Table III.III) & Log of 3-year average income & Men & Sweden & 0.49 & 0.29 & 0.40 & 0.09 & 0.51 \\
\hline Benjamin et al. (2012, Table 1) & Average of 20 year log incomes & Men & Sweden & 0.63 & 0.27 & 0.63 & 0.00 & 0.37 \\
\hline Benjamin et al. (2012, Table 1) & Average of 20 year log incomes & Women & Sweden & 0.48 & 0.22 & 0.48 & 0.00 & 0.52 \\
\hline Benjamin et al. (2012, Table 1$)$ & Average of 5 year log incomes & Men & Sweden & 0.51 & 0.20 & 0.51 & 0.00 & 0.49 \\
\hline Benjamin et al. (2012, Table 1) & Average of 5 year log incomes & Women & Sweden & 0.30 & 0.20 & 0.20 & 0.10 & 0.70 \\
\hline Benjamin et al. (2012, Table 1$)$ & Log of annual income & Men & Sweden & 0.41 & 0.16 & 0.41 & 0.00 & 0.59 \\
\hline \multirow[t]{4}{*}{ Benjamin et al. (2012, Table 1$)$} & Log of annual income & Women & Sweden & 0.27 & 0.14 & 0.25 & 0.02 & 0.73 \\
\hline & & & Avg. U.S. & 0.50 & 0.28 & 0.41 & 0.09 & 0.50 \\
\hline & & & Avg. Australia & 0.58 & 0.32 & 0.45 & 0.13 & 0.42 \\
\hline & & & Avg. Sweden & 0.44 & 0.22 & 0.40 & 0.05 & 0.56 \\
\hline
\end{tabular}

Notes: $h^{2}=2^{*}\left(r_{M z}-r_{D z}\right), c^{2}=r_{M z}-h^{2}$, and $e^{2}=1-h^{2}-c^{2}$ refer to the standard additive behavioral genetics variance decomposition. In the cases where this decomposition gives a negative value for $\mathrm{c}^{2}$, it has been set to zero, and the corresponding value has been deducted from $\mathrm{h}^{2}$. Earnings (income) data refer to a cross-section in the US and Australian studies. Ashenfelter and Rouse (1998) average the income over time for those twins (25\% of the sample) who were interviewed more than once. They do not show the correlations, but those are reported in Harding et al. (2005, fn. 4). In Miller et al. (1995, 1997) the earnings measure is the average full time income from the occupation of employment, measured at the level of 2-digit, gender-specific occupational groups (i.e., it is not measured at the level of individuals). Isacsson (1999) and Björklund et al. (2005) use incomes from 3 years over a 7-year period and Cesarini (2010) from 3 years over a 5-year period. Benjamin et al. (2012) use data from consecutive years. They also show the correlations for 10-year and 3year average log incomes, which are not reported here. Most of the multi-year studies adjust the incomes for age. 
Table 2: Descriptive statistics

\begin{tabular}{|c|c|c|c|c|}
\hline & \multicolumn{2}{|c|}{ Females } & \multicolumn{2}{|c|}{ Males } \\
\hline & $\mathrm{MZ}$ & DZ & $\mathrm{MZ}$ & DZ \\
\hline \multicolumn{5}{|l|}{ Income $(€)$} \\
\hline Average & 17523.55 & 17701.65 & 24433.08 & 24016.11 \\
\hline Standard deviation & 9711.76 & 16306.19 & 18975.87 & 13789.08 \\
\hline \multicolumn{5}{|l|}{ Log(income) } \\
\hline Average & 9.49 & 9.48 & 9.76 & 9.77 \\
\hline Standard deviation & 0.74 & 0.76 & 0.87 & 0.84 \\
\hline \multicolumn{5}{|l|}{ Age 1990 (years) } \\
\hline Average & 36.3 & 36.2 & 36.3 & 36.4 \\
\hline Standard deviation & 2.3 & 2.3 & 2.3 & 2.2 \\
\hline $\begin{array}{l}\text { Correlations of age adjusted } \\
\text { average log(income), } r_{\mathrm{MZ}} \text { and } \mathrm{r}_{\mathrm{DZ}}\end{array}$ & 0.339 & 0.220 & 0.535 & 0.150 \\
\hline Number of twin pairs & 620 & 1146 & 494 & 1094 \\
\hline Number of persons & 1240 & 2292 & 988 & 2188 \\
\hline
\end{tabular}


Table 3: $A C E, A E$, and $A D E$-regressions

\begin{tabular}{lccccccc}
\hline & \multicolumn{3}{c}{ Females } & & \multicolumn{3}{c}{ Males } \\
\cline { 2 - 5 } \cline { 6 - 8 } & ACE & AE & ADE & & ACE & AE & ADE \\
\hline$\beta_{1}$ & 0.10 & & & & -0.23 & & \\
& $(0.08)$ & & & & $(0.08)$ & & \\
$\beta_{2}$ & 0.04 & 0.06 & 0.04 & & 0.09 & 0.05 & 0.09 \\
& $(0.04)$ & $(0.04)$ & $(0.04)$ & & $(0.05)$ & $(0.05)$ & $(0.05)$ \\
$\beta_{3}$ & 0.24 & 0.37 & 0.54 & & 0.77 & 0.45 & 0.07 \\
& $(0.11)$ & $(0.04)$ & $(0.14)$ & & $(0.11)$ & $(0.04)$ & $(0.13)$ \\
$\beta_{4}$ & & & -0.20 & & & & 0.47 \\
& & & $(0.16)$ & & & & $(0.15)$ \\
$\beta_{0}$ & -0.11 & -0.12 & -0.11 & & -0.15 & -0.12 & -0.15 \\
& $(0.03)$ & $(0.03)$ & $(0.03)$ & & $(0.04)$ & $(0.03)$ & $(0.04)$ \\
\hline AIC: & 7707.4 & 7709.8 & 7707.4 & & 7565.3 & 7585.0 & 7565.3 \\
N(pairs): & 1766 & 1766 & 1766 & & 1588 & 1588 & 1588 \\
F-statistic: & & & 61.2 & & & 148.22 \\
p-value & & & $<0.01$ & & & $<0.01$ \\
\hline \hline
\end{tabular}

Notes: Standard errors in parentheses, clustered at twin pair level. AIC is the Akaike information criterion. The F-statistic and $p$-value refer to the test that the sum of narrowsense heritability and dominance effect is zero, i.e., $\beta_{3}+\beta_{4}=0$. 
Table 4: $A C E, A E$, and $A D E$-regressions with education

Panel A: Education included as a regressor

\begin{tabular}{|c|c|c|c|c|c|c|}
\hline & \multicolumn{3}{|c|}{ Females } & \multicolumn{3}{|c|}{ Males } \\
\hline & ACE & $\mathrm{AE}$ & ADE & ACE & $A E$ & ADE \\
\hline \multirow[t]{2}{*}{$\beta_{1}$} & 0.08 & & & -0.25 & & \\
\hline & $(0.07)$ & & & $(0.07)$ & & \\
\hline \multirow[t]{2}{*}{$\beta_{2}$} & 0.0003 & 0.01 & 0.0003 & 0.002 & -0.04 & 0.002 \\
\hline & $(0.04)$ & $(0.04)$ & $(0.04)$ & $(0.05)$ & $(0.05)$ & $(0.05)$ \\
\hline \multirow[t]{2}{*}{$\beta_{3}$} & 0.19 & 0.31 & 0.45 & 0.71 & 0.37 & -0.04 \\
\hline & $(0.10)$ & $(0.03)$ & $(0.13)$ & $(0.10)$ & $(0.04)$ & $(0.12)$ \\
\hline \multirow[t]{2}{*}{$\beta_{4}$} & & & -0.17 & & & 0.50 \\
\hline & & & $(0.15)$ & & & $(0.14)$ \\
\hline \multirow[t]{2}{*}{$\beta_{0}$} & -1.05 & -1.06 & -1.05 & -1.17 & -1.13 & -1.17 \\
\hline & $(0.07)$ & $(0.07)$ & $(0.07)$ & $(0.07)$ & $(0.07)$ & $(0.07)$ \\
\hline \multirow[t]{2}{*}{ Education } & 0.08 & 0.08 & 0.08 & 0.09 & 0.09 & 0.09 \\
\hline & $(0.01)$ & $(0.01)$ & $(0.01)$ & $(0.01)$ & $(0.01)$ & $(0.01)$ \\
\hline AIC: & 7453.9 & 7455.2 & 7453.9 & 7307.9 & 7333.0 & 7307.9 \\
\hline$N($ pairs): & 1766 & 1766 & 1766 & 1588 & 1588 & 1588 \\
\hline F-statistic & & & 44.70 & & & 112.62 \\
\hline$p$-value & & & $<0.01$ & & & $<0.01$ \\
\hline
\end{tabular}

Panel B: Education effect deducted from income

\begin{tabular}{lccccccc} 
& \multicolumn{3}{c}{ Females } & & \multicolumn{3}{c}{ Males } \\
\cline { 2 - 5 } \cline { 6 - 8 } & ACE & AE & ADE & & ACE & AE & ADE \\
\hline$\beta_{1}$ & 0.09 & & & & -0.29 & & \\
& $(0.08)$ & & & & $(0.08)$ & & \\
$\beta_{2}$ & 0.16 & 0.26 & 0.16 & & 0.81 & 0.37 & 0.81 \\
& $(0.10)$ & $(0.05)$ & $(0.10)$ & & $(0.13)$ & $(0.06)$ & $(0.13)$ \\
$\beta_{3}$ & 0.21 & 0.33 & 0.48 & & 0.79 & 0.39 & -0.09 \\
& $(0.11)$ & $(0.04)$ & $(0.14)$ & & $(0.11)$ & $(0.04)$ & $(0.13)$ \\
$\beta_{4}$ & & & -0.18 & & & & 0.58 \\
& & & $(0.16)$ & & & & $(0.16)$ \\
$\beta_{0}$ & -0.72 & -0.80 & -0.72 & & -1.37 & -1.06 & -1.37 \\
& $(0.07)$ & $(0.03)$ & $(0.07)$ & & $(0.09)$ & $(0.03)$ & $(0.09)$ \\
\hline AIC: & 7484.7 & 7486.3 & 7484.7 & & 7314.6 & 7345.0 & 7314.6 \\
N(pairs): & 1865 & 1865 & 1865 & & 1674 & 1674 & 1674 \\
F-statistic & & & 45.62 & & & 111.80 \\
p-value & & & $<0.01$ & & & $<0.01$ \\
\hline \hline
\end{tabular}

Notes: Standard errors in parentheses, clustered at twin pair level. AIC is the Akaike information criterion. The F-statistic and $p$-value refer to the test that the sum of narrow-sense heritability and dominance effect is zero, i.e., $\beta_{3}+\beta_{4}=0$. 
Table 5: Annual regressions of the share of genetic heritability

\begin{tabular}{lcc}
\hline & $h^{2}, A E$ & $h^{2}, A D E$ \\
\hline Female & -0.093 & -0.134 \\
& $(0.024)$ & $(0.021)$ \\
GDP growth & 0.002 & 0.005 \\
& $(0.002)$ & $(0.002)$ \\
Gini index & 0.004 & 0.010 \\
& $(0.004)$ & $(0.005)$ \\
Constant & 0.217 & 0.077 \\
& $(0.102)$ & $(0.144)$ \\
\hline $\mathrm{R}^{2}:$ & 0.51 & 0.71 \\
$\mathrm{~N}:$ & 30 & 30 \\
\hline \hline Notes: Standard errors in parentheses, \\
clustered at the year level.
\end{tabular}

Table 6: Descriptive statistics of income risk

\begin{tabular}{lccccc}
\hline & \multicolumn{2}{c}{ Females } & & \multicolumn{2}{c}{ Males } \\
\cline { 2 - 3 } \cline { 5 - 6 } & $\mathrm{MZ}$ & $\mathrm{DZ}$ & & $\mathrm{MZ}$ & $\mathrm{DZ}$ \\
\hline Average & 0.47 & 0.47 & & 0.45 & 0.45 \\
Standard deviation & 0.43 & 0.42 & & 0.45 & 0.43 \\
Correlations of income risk, & 0.155 & 0.104 & & 0.341 & 0.097 \\
$\mathrm{r}_{\mathrm{MZ}}$ and $\mathrm{r}_{\mathrm{DZ}}$ & & & & & \\
Number of twin pairs & 606 & 1125 & & 486 & 1073 \\
Number of persons & 1212 & 2250 & & 972 & 2146 \\
\hline \hline
\end{tabular}

Notes: The income risk is calculated by regressing log(income) on year dummies and a third degree polunomial of age using data on all persons in 1990-2004 and by calculating within-person standard deviation of the residual. 
Table 7: $A C E, A E$, and $A D E$-regressions for income risk

\begin{tabular}{lccccccc}
\hline & \multicolumn{3}{c}{ Females } & & \multicolumn{3}{c}{ Males } \\
\cline { 2 - 5 } \cline { 6 - 8 } & ACE & AE & ADE & & ACE & AE & ADE \\
\hline$\beta_{1}$ & 0.05 & & & & -0.15 & & \\
& $(0.08)$ & & & & $(0.08)$ & & \\
$\beta_{2}$ & -0.05 & -0.09 & -0.05 & & -0.21 & -0.12 & -0.21 \\
& $(0.06)$ & $(0.03)$ & $(0.06)$ & & $(0.06)$ & $(0.03)$ & $(0.06)$ \\
$\beta_{3}$ & 0.10 & 0.17 & 0.26 & & 0.49 & 0.29 & 0.05 \\
& $(0.11)$ & $(0.04)$ & $(0.14)$ & & $(0.11)$ & $(0.04)$ & $(0.13)$ \\
$\beta_{4}$ & & & -0.11 & & & & 0.30 \\
& & & $(0.16)$ & & & & $(0.15)$ \\
$\beta_{0}$ & 0.45 & 0.48 & 0.45 & & 0.51 & 0.44 & 0.51 \\
& $(0.04)$ & $(0.02)$ & $(0.04)$ & & $(0.04)$ & $(0.02)$ & $(0.04)$ \\
\hline AIC: & 3796.9 & 3795.9 & 3796.9 & 3577.1 & 3583.0 & 3577.1 \\
N(pairs): & 1731 & 1731 & 1731 & & 1559 & 1559 & 1559 \\
F-statistic & & & 11.32 & & & 50.64 \\
p-value & & & $<0.01$ & & & $<0.01$ \\
\hline \hline
\end{tabular}

Notes: Standard errors in parentheses, clustered at twin pair level. AIC is the Akaike information criterion. The F-statistic and $p$-value refer to the test that the sum of narrow-sense heritability and dominance effect is zero, i.e., $\beta_{3}+\beta_{4}=0$. 
Figure 1: Annual variation in heritability estimates

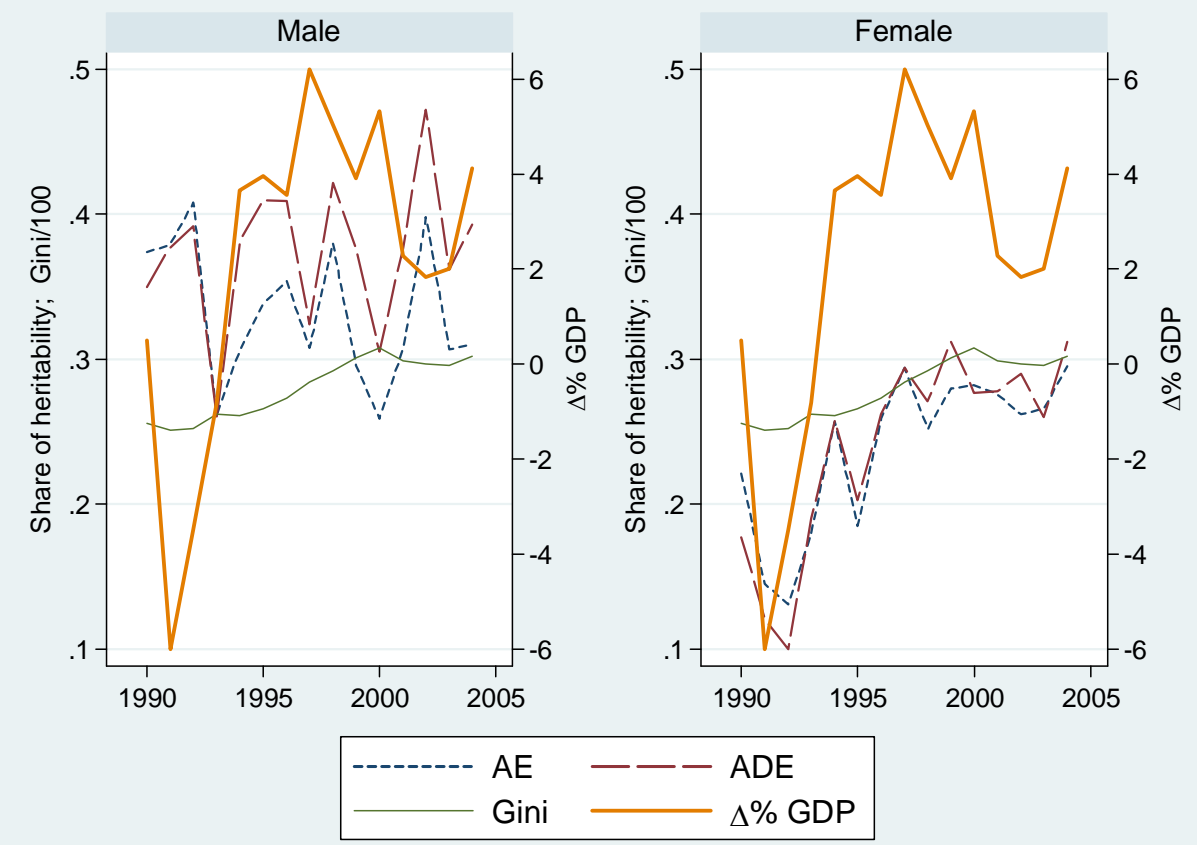


Appendix 1. Robustness analysis: Lifetime income

Table A1: ACE, AE, and ADE -regressions for those born 1945 or later

\begin{tabular}{|c|c|c|c|c|c|c|}
\hline & \multicolumn{3}{|c|}{ Females } & \multicolumn{3}{|c|}{ Males } \\
\hline & ACE & $\mathrm{AE}$ & ADE & ACE & $\mathrm{AE}$ & ADE \\
\hline \multirow[t]{2}{*}{$\beta_{1}$} & -0.01 & & & -0.12 & & \\
\hline & $(0.07)$ & & & $(0.07)$ & & \\
\hline \multirow[t]{2}{*}{$\beta_{2}$} & 0.06 & 0.05 & 0.06 & 0.07 & 0.05 & 0.07 \\
\hline & $(0.04)$ & $(0.04)$ & $(0.04)$ & $(0.04)$ & $(0.04)$ & $(0.04)$ \\
\hline \multirow[t]{2}{*}{$\beta_{3}$} & 0.35 & 0.33 & 0.31 & 0.62 & 0.46 & 0.25 \\
\hline & $(0.10)$ & $(0.03)$ & $(0.12)$ & (0.10) & $(0.03)$ & $(0.11)$ \\
\hline \multirow[t]{2}{*}{$\beta_{4}$} & & & 0.03 & & & 0.25 \\
\hline & & & $(0.14)$ & & & $(0.13)$ \\
\hline \multirow[t]{2}{*}{$\beta_{0}$} & -0.13 & -0.13 & -0.13 & -0.15 & -0.13 & -0.15 \\
\hline & $(0.03)$ & $(0.03)$ & $(0.03)$ & $(0.03)$ & $(0.03)$ & $(0.03)$ \\
\hline AIC: & 12424.2 & 12422.3 & 12424.2 & 12729.0 & 12736.6 & 12729.0 \\
\hline$N($ pairs): & 2694 & 2694 & 2694 & 2562 & 2562 & 2562 \\
\hline F-statistic: & & & 60.15 & & & 149.07 \\
\hline $\mathrm{p}$-value & & & $<0.01$ & & & $<0.01$ \\
\hline
\end{tabular}


Table A2: $A C E, A E$, and ADE-regressions for taxable income

\begin{tabular}{|c|c|c|c|c|c|c|}
\hline \multirow[t]{3}{*}{ Panel A: Females } & \multirow{2}{*}{\multicolumn{3}{|c|}{ Females }} & \multirow{2}{*}{\multicolumn{3}{|c|}{ Males }} \\
\hline & & & & & & \\
\hline & ACE & $\mathrm{AE}$ & $A D E$ & ACE & $\mathrm{AE}$ & ADE \\
\hline \multirow[t]{2}{*}{$\beta_{1}$} & -0.04 & & & -0.16 & & \\
\hline & $(0.08)$ & & & $(0.08)$ & & \\
\hline \multirow[t]{2}{*}{$\beta_{2}$} & 0.02 & 0.02 & 0.02 & 0.02 & 0.01 & 0.02 \\
\hline & $(0.03)$ & (0.03) & $(0.03)$ & $(0.03)$ & $(0.03)$ & $(0.03)$ \\
\hline \multirow[t]{2}{*}{$\beta_{3}$} & 0.47 & 0.42 & 0.35 & 0.75 & 0.53 & 0.26 \\
\hline & $(0.12)$ & (0.04) & $(0.14)$ & $(0.10)$ & $(0.03)$ & $(0.14)$ \\
\hline \multirow[t]{2}{*}{$\beta_{4}$} & & & 0.08 & & & 0.33 \\
\hline & & & $(0.16)$ & & & $(0.15)$ \\
\hline \multirow[t]{2}{*}{$\beta_{0}$} & -0.04 & -0.04 & -0.04 & -0.03 & -0.03 & -0.03 \\
\hline & $(0.02)$ & $(0.02)$ & $(0.02)$ & $(0.03)$ & $(0.03)$ & $(0.03)$ \\
\hline AIC: & 6389.0 & 6387.8 & 6389.0 & 6186.3 & 6195.9 & 6186.3 \\
\hline $\mathrm{N}$ (pairs): & 1850 & 1850 & 1850 & 1664 & 1664 & 1664 \\
\hline F-statistic: & & & 79.43 & & & 290.94 \\
\hline$p$-value & & & $<0.01$ & & & $<0.01$ \\
\hline
\end{tabular}




\section{Appendix 2. Robustness analysis: The Björklund, Jäntti and Solon results and the Bowles and Gintis -model}

In this appendix we check the robustness of our main heritability results to the observations made by Björklund, Jäntti and Solon (2005). To achieve this goal we use the heritability model of Bowles and Gintis (2002). The two key correlation moments of the model are (see Bowles and Gintis 2002, p. 23-27, especially their equations (8) and (9)):

$$
\begin{aligned}
& r_{y_{1} y_{2}}^{M Z}=\beta_{e}{ }^{2}\left({\beta_{E}}^{2}+\beta_{g e}{ }^{2}\right)+h^{2}+2 \beta_{e} \beta_{g e} h \\
& r_{y_{1} y_{2}}^{D Z}=\beta_{e}{ }^{2}\left({\beta_{E}}^{2}+\left(1+m_{y}\right) \frac{1}{2} \beta_{g e}{ }^{2}\right)+\left(1+m_{y}\right) \frac{1}{2} h^{2}+\left(1+m_{y}\right) \frac{1}{2} \beta_{e} \beta_{g e} h
\end{aligned}
$$

where $r_{y_{1} y_{2}}^{M Z}$ and $r_{y_{1} y_{2}}^{D Z}$ refer to the within MZ and DZ -pair correlations (of income), $h$ is the square root of the heritability of income; $\beta_{g e}$ is a parameter that allows for a non-zero gene-environment correlation, $m_{y}$ is a parameter that allows for a non-zero correlation between the maternal and paternal genes (i.e. assortative mating), and where $\beta_{e}$ and $\beta_{E}$ are (path) parameters such that $\beta_{e}{ }^{2} \beta_{E}{ }^{2} \equiv c^{2}$, which denotes the importance of the shared environment. The model also allows for an unequal shared environment for the MZ and DZ twins. It is easy to see that if $m_{y}=\beta_{g e}=0$, the model reduces to the standard additive model, as then $h^{2}=2\left(r_{y_{1} y_{2}}^{M Z}-r_{y_{1} y_{2}}^{D Z}\right)$ and $c^{2}=\beta_{e}^{2} \beta_{E}^{2}=r_{y_{1} y_{2}}^{M Z}-h^{2}$.

The models of Björklund et al. (2005) allow, one at the time, for non-random mating, a nonzero gene-environment correlation, and a shared environment of the DZ twins that is different from that of the MZ twins. Their findings from these various models suggest that $i$ ) the correlation of DZ twins’ genotypes, $\left(1+m_{y}\right) \frac{1}{2}$ (see, Bowles and Gintis, 2002, p. 26 for this expression), may be about 0.43 for males ( 0.39 for females), as opposed to 0.5 of the standard model; that ii) the geneenvironment correlation is negative (but small in absolute value and insignificant statistically); and that iii) for male (female) DZ twins, the correlation of environments may be as low as 0.406 (0.282), when the corresponding correlation for the MZ twins is standardized to one. Given the similarity of the Nordic countries, it seems prudent that we consider these values in our robustness tests.

The results are displayed in Table A3, separately for women (Panel A) and men (Panel B). Each panel has three sub-panels. In the first sub-panels, we impose $\beta_{g e}=0$ but allow $m_{y}$ to vary from -0.22 to 0.20 for females and from -0.14 to 0.20 for males, where the lower bounds match with the estimates of Björklund et al. (2005). For the second sub-panels, we impose $m_{y}=0$ (i.e., random 
mating), but allow $\beta_{g e}$ to vary from -0.20 to 0.20 . Finally, for the third sub-panels, we set the correlation of environments to be 0.406 for DZ females and 0.282 for DZ males (with the corresponding correlation for the MZ twins standardized to one), and study what this implies in the light of the Bowles and Gintis model for $\beta_{g e}$ aid $m_{y}$.

Let us first focus on the results reported in the first two sub-panels. These results support our main qualitative findings, both for females and males. They show, in particular, that the heritability estimates, $h^{2}$, do not change dramatically, relative to the standard model (for which the results are displayed in the first two columns of each sub-panel) or relative to what we report in the main text. It is, moreover, worth noting that the shared environmental effect is always negative for males. In particular, in the Bowles and Gintis model, $c^{2}=r_{y_{1} y_{2}}^{M Z}-\frac{2}{\left(1-m_{y}\right)} \Delta r_{y_{1} y_{2}}$ is positive only if $m_{y}<2 \frac{r_{D Z}}{r_{M Z}}-1$. When $r_{y_{1} y_{2}}^{M Z}$ is more than twice times $r_{y_{1} y_{2}}^{D Z}$ (as is the case in our data for males), this calls for a sufficiently negative estimate for $m_{y}$, i.e. "inverse assortative mating”. However, as the first sub-panel (in Panel B) shows, the estimate that we obtain from Björklund et al. (2005) for $m_{y}$ is not sufficiently negative to generate a positive estimate for $c^{2}$. Note also that in the Bowles and Gintis model, the correlation of DZ twins' environments, denoted $\rho_{e 1, e 2}^{D Z}$ in the table, does not vary with $m_{y}$ if $\beta_{g e}=0$. However, $\rho_{e 1, e 2}^{D Z}$, varies with $\beta_{g e}$ even if $m_{y}=0$, as the second sub-panels show.

If we then turn to the third sub-panels, we find that the estimates that Björklund et al. (2005) obtain for the correlation of the DZ environments imply, according to the Bowles and Gintis model, very large negative values for $m_{y}$ and very high (absolute) values for $\beta_{g e}$. Such numbers are not consistent with their other estimates, which suggest (much) smaller negative values for $m_{y}$ and small values for $\beta_{g e}$. 
Table A3: Bowles-Gintis model

Panel A: Females

Correlations:

\begin{tabular}{|c|c|c|c|c|c|c|}
\hline & & $r_{M Z}$ & & $r_{D Z}$ & & \\
\hline & & 0.339 & & 0.220 & & \\
\hline Basic dec & position & & Bowles- & tis deco & position & \\
\hline$h^{2}$ & $c^{2}$ & $h^{2}$ & $c^{2}$ & $\rho^{\mathrm{DZ}}{ }_{\mathrm{e} 1 \mathrm{e} 2}$ & $\beta_{\mathrm{ge}}$ & $m_{y}$ \\
\hline 0.238 & 0.101 & 0.195 & 0.144 & 1.000 & 0.000 & -0.220 \\
\hline 0.238 & 0.101 & 0.198 & 0.141 & 1.000 & 0.000 & -0.200 \\
\hline 0.238 & 0.101 & 0.216 & 0.123 & 1.000 & 0.000 & -0.100 \\
\hline 0.238 & 0.101 & 0.238 & 0.101 & 1.000 & 0.000 & 0.000 \\
\hline 0.238 & 0.101 & 0.264 & 0.075 & 1.000 & 0.000 & 0.100 \\
\hline 0.238 & 0.101 & 0.298 & 0.042 & 1.000 & 0.000 & 0.200 \\
\hline 0.238 & 0.101 & 0.306 & 0.101 & 0.980 & -0.200 & 0.000 \\
\hline 0.238 & 0.101 & 0.270 & 0.101 & 0.995 & -0.100 & 0.000 \\
\hline 0.238 & 0.101 & 0.238 & 0.101 & 1.000 & 0.000 & 0.000 \\
\hline 0.238 & 0.101 & 0.208 & 0.101 & 0.995 & 0.100 & 0.000 \\
\hline 0.238 & 0.101 & 0.179 & 0.101 & 0.980 & 0.200 & 0.000 \\
\hline 0.238 & 0.101 & - & - & 0.282 & 0.850 & -0.988 \\
\hline 0.238 & 0.101 & - & - & 0.282 & 0.900 & -0.773 \\
\hline 0.238 & 0.101 & - & - & 0.282 & 0.950 & -0.591 \\
\hline 0.238 & 0.101 & - & - & 0.282 & -0.850 & -0.988 \\
\hline 0.238 & 0.101 & - & - & 0.282 & -0.900 & -0.773 \\
\hline 0.238 & 0.101 & - & - & 0.282 & -0.950 & -0.591 \\
\hline
\end{tabular}


Table A3: Bowles-Gintis model (continued)

Panel B: Males

\begin{tabular}{|c|c|c|c|c|c|c|}
\hline \multicolumn{7}{|c|}{ Correlations: } \\
\hline & & $r_{M Z}$ & & $r_{D Z}$ & & \\
\hline & & 0.535 & & 0.150 & & \\
\hline \multicolumn{2}{|c|}{ Basic decomposition } & \multicolumn{5}{|c|}{ Bowles-Gintis decomposition } \\
\hline$h^{2}$ & $c^{2}$ & $h^{2}$ & $c^{2}$ & $\rho^{\mathrm{DZ}}{ }_{\mathrm{e} 1 \mathrm{e} 2}$ & $\beta_{\mathrm{ge}}$ & $\mathrm{m}_{\mathrm{y}}$ \\
\hline 0.770 & -0.235 & 0.675 & -0.140 & 1.000 & 0.000 & -0.140 \\
\hline 0.770 & -0.235 & 0.700 & -0.165 & 1.000 & 0.000 & -0.100 \\
\hline 0.770 & -0.235 & 0.733 & -0.198 & 1.000 & 0.000 & -0.050 \\
\hline 0.770 & -0.235 & 0.770 & -0.235 & 1.000 & 0.000 & 0.000 \\
\hline 0.770 & -0.235 & 0.963 & -0.428 & 1.000 & 0.000 & 0.200 \\
\hline 0.770 & -0.235 & 0.963 & -0.428 & 1.000 & 0.000 & 0.200 \\
\hline 0.770 & -0.235 & na & -0.235 & 0.980 & -0.200 & 0.000 \\
\hline 0.770 & -0.235 & na & -0.235 & 0.995 & -0.100 & 0.000 \\
\hline 0.770 & -0.235 & 0.770 & -0.235 & 1.000 & 0.000 & 0.000 \\
\hline 0.770 & -0.235 & na & -0.235 & 0.995 & 0.100 & 0.000 \\
\hline 0.770 & -0.235 & na & -0.235 & 0.980 & 0.200 & 0.000 \\
\hline 0.770 & -0.235 & - & - & 0.406 & 0.850 & -0.644 \\
\hline 0.770 & -0.235 & - & - & 0.406 & 0.900 & -0.467 \\
\hline 0.770 & -0.235 & - & - & 0.406 & 0.950 & -0.316 \\
\hline 0.770 & -0.235 & - & - & 0.406 & -0.850 & -0.644 \\
\hline 0.770 & -0.235 & - & - & 0.406 & -0.900 & -0.467 \\
\hline 0.770 & -0.235 & - & - & 0.406 & -0.950 & -0.316 \\
\hline
\end{tabular}

